\title{
Drug Addiction In Pakistan: A step towards alleviation of sufferings
}

\author{
Ali Burhan Mustafa, ${ }^{1}$ Bisma Jamil ${ }^{1}$
}

Addiction is a complex mental and behavioral disorder that changes the neurochemistry and physiology of the brain. Genetics also plays a significant role in the pathophysiology of addiction. ${ }^{1}$ Drug addiction, whether it is mono or poly drug addiction is a major problem in Pakistan, it is defined as a maladaptive form of drug or illicit use leading to clinically significant distress or impairment, while an individual may also suffer from withdrawal and tolerance. As we know that drug addiction or abuse is a common problem worldwide, including Pakistan. ${ }^{2}$ According to World Health Organization (WHO), Pakistan is categorized as low income country of Eastern Mediterranean Regional Office (EMRO) region with a population of more than 20 million people among which, 97\% of Pakistani population is predominantly Muslim, with highly conventional customs and traditions governing the lives of many people. These people showed to follow Islamic and cultural norms and values. All substances of abuse are publicly despised in Pakistani culture, also in their religion. Usage of drugs consider harmful and known to be prevalent among people. Government does warranting determinations to increase awareness about harmful effects of drugs and to change attitudes of people and prevention of the addiction. ${ }^{3}$

In Pakistan, the prevalence of drug addiction is increasing at an alarming rate. According to United Nations Office on Drugs and Crime (UNDOC) and the reports of United Nations (UN), Pakistan has 7.6 million drug addicts, where $78 \%$ are males and $22 \%$ are females. ${ }^{4,5}$ However, the risk factors, which are increasing vulnerability towards addiction, remain largely elusive. The ratio of the problem of substance has increased and not decreased by any effort of the government. Pakistan became a marked trafficking route for illicit drugs, especially heroin, due to increased opium production in Afghanistan, and 2670 kilometers land border of Afghanistan is shared with Pakistan. Most of the drugs come from Afghanistan, a country that is held responsible for $75 \%$ of the world's heroin. UNDOC estimates that 800,000 Pakistanis aged between 15 and 64 used heroin regularly. Drug use or abuse became a more divergent dilemma in Pakistan, that's why Government of Pakistan takes a very serious notice of this matter of use, or addiction of illicit drugs or substance. ${ }^{6}$

Substances categorized as stimulants, sedatives, hallucinogens and opioids are being abused throughout the world including Pakistan. Addiction to opioids including other illicit substances is a chronic, relapsing multifactorial disorder of brain and, if left untreated, major medical, social, and economic problems arise. Substance addiction is among major health issues faced by the world including Pakistan. Its effect on physical and psychological health and become leading cause of other problems. Drug addiction can also be known as an initial chronic neurological problem, with hereditary, psychological, social, environmental and cognitive features that influence development and appearance of an individual or a person. Different behaviors as like the disturbed control or impulsivity for substance abuse and constant use of illicit substances deprived of harmful effects occurs due to addiction of drug. ${ }^{3}$ Substance use disorder such as opium, alcohol or other illicit substances is very serious community health problems now a days in Pakistan. Drug addiction is also associated with many risk factors like aggression, violence, isolation and emotion dysregulation. There are many established and significant psychosocial risk factors like parental relationship, lack of achievement and motivation, self-esteem, psychological stress and attention seeking behavior that are found positively correlated with substance abuse or addiction in Pakistan.

A person who is stigmatized as addict has more negative social support from friends, family and others. The major reason behind this is that a person, who is dependent of drugs, has been rejected by the society due to substance addiction or his addictive behavior, but sometime a drug dependence has positive approach towards their friends and family because both support them in a good way, to take them away from the curse of addiction. While, those friends who never respond positively to drug dependence and 
they may be the cause for their substance usage, and may lead towards severe aggression and emotion dysregulation. ${ }^{6}$ Effects of substance addiction are always negative, it confirm that after substance addiction the addicts exhibit highly careless manners. Their income drop down and they reduce economic contribution in nourishment of their family. Mostly their earning is consumed on buying substance. ${ }^{7}$ The dependent members are liberated from dependence of addicts as they start economic activities of their own or the addicts are not capable of earning, hence deserted. The addicts lead miserable life as they remain under heavy debt as they take loan from friends and their poor health demand high expenditure with low economic performance. Drug abuse is hazardous and known to be prevalent among people, there is need to increase awareness about harmful effects and to change attitudes. ${ }^{7}$ There is need of educating our society specially students about the adverse effects and the moral and religious implications of substance abuse is more likely to have a positive impact than increased policing and prevention of drug use. There is lack studentcounseling facilities, awareness programs, and rehabilitation centers in Pakistan. The health system need more progress for the prevention of drug addiction.

Department of Psychiatry \& Behavioral Sciences, inaugurated the 13-bedded Centre for Drug Addiction and Rehabilitation Centre at Sheikh Zayed Medical College/Hospital, Rahim Yar Khan on 20th February, 2020 in order to make the genuine effort towards the alleviation of sufferings. The vision is to transform the newly established center into the model addicts treatment and rehabilitation center (MATRCs).

Dr. Ali Burhan Mustafa
Associate Professor
Department of Psychiatry \& Behavioral Sciences
Sheikh Zayed Medical College/Hospital
Rahim Yar Khan, Pakistan
aliburhanmustafa@gmail.com

\section{References}

1. Datta U, Schoenrock SE, Bubier JA, Bogue MA, Jentsch JD, Logan RW, et al. Prospects for finding the mechanisms of sex differences in addiction with human and model organism genetic analysis. Genes, Brain and Behavior. 2020 Feb 3.

2. Ali M, Abbasi BH, Ahmad N, Fazal H, Khan J, Ali SS. Over-the-counter medicines in Pakistan: misuse and overuse. The Lancet. 2020 Jan 11;395(10218):116.

3. Mustafa A. Impact of Poly-drug and Mono-drug on Aggression and Emotional Dysregulation among Substance Users. Journal of Pakistan Psychiatric Society. 2019 Dec 20;16(4).

4. $\quad$ Drug, Report. "UN Report". Available at: Unodc.org/unodc/en/data-and-analysis/wdr2021.html

5. Drugged up Pakistan. Al-Jazeera. 10 October 2014. Retrieved 18 March 2015.

6. Saleem M, Tahir MA, Ul Huda N. Perceived social support and clinical anger among drug addicts of southern Punjab, Pakistan. Pakistan Journal of Commerce and Social Sciences (PJCSS). 2013;7(2):298-308.

7. Daley J, Elliott FJ, Gibbs TM, Kitteringham G. Substance Abuse. InThe Professional Protection Officer 2020 Jan 1 (pp. 233-252). 